\title{
Pengaruh Komitmen Perusahaan Terhadap Loyalitas Pelanggan Supermarket di Kota Manado
}

\author{
Robby Tanod Mamusung ${ }^{1, *}$ dan Effendy Rasjid ${ }^{2}$ \\ ${ }^{1,2}$ Jurusan Administrasi Bisnis, Politeknik Negeri Manado \\ *Email: mamusungrobby@gmail.com
}

\begin{abstract}
The objective developed from this study was to test and analyze the effect of corporate commitment on customer loyalty in the retail industry. In such an industry, corporate commitment is the key to improve the firm competitiveness. The study was carried out in Manado City with 70 supermarket customers as sample. The sampling technique was purposive sampling. The research conclude that corporate commitment has positive and significant effect on customer loyalty. The finding was in line with the concept of Commitment - Trust Theory, stating that Commitment-Trust is two based factors relationship marketing interaction would give a success relationship so that it would improve customer trust and eventually they would be back to shop more. The implication of this managerial research conclusion was that the supermarket leader in Manado city must focus and emphasize more on the dimension of corporate commitment especially in terms of room is roomy or not cramped in the supermarket. Once they could be met, then costumer trust would increase, and it led to an increase in customer loyalty to shopping more and invites others to shop at the supermarket. The research limitation was the limited area of research. It should be broader for the next research so that the better conceptual model could be generalized.
\end{abstract}

Abstraksi: Tujuan yang dikembangkan dari penelitian adalah untuk menguji dan menganalisis pengaruh komitmen perusahaan terhadap loyalitas pelanggan, terutama di industri ritel. Dalam industri seperti itu, komitmen perusahaan adalah kunci untuk meningkatkan daya saing. Penelitian dilakukan di Kota Manado dengan jumlah sampel 70 pelanggan supermarket. Teknik penarikan sampel menggunakan purposive sampling. Hasil penelitian menyimpulkan bahwa komitmen perusahaan berpengaruh secara positif serta signifikan terhadap variabel loyalitas pelanggan. Temuan tersebut sejalan dengan konsep Teori Komitmen Kepercayaan, yang menyatakan bahwa Komitmen-Kepercayaan adalah dua faktor yang mendasari interaksi pemasaran yang akan memberikan hubungan yang sukses sehingga akan meningkatkan kepercayaan pelanggan dan akhirnya mereka akan kembali berbelanja lebih banyak. Implikasi dari penelitian manajerial tersebut adalah bahwa pemimpin supermarket di kota Manado harus lebih fokus dan lebih menekankan pada dimensi komitmen perusahaan terutama dalam hal penataan ruang toko yang lapang atau tidak sempit di supermarket. Begitu mereka dapat bertemu, maka kepercayaan pelanggan akan meningkat, dan itu menyebabkan peningkatan loyalitas pelanggan untuk berbelanja lebih banyak dan mengundang orang lain untuk berbelanja di supermarket. Keterbatasan penelitian ini adalah bidang penelitian yang terbatas, oleh karena itu, ruang lingkup wilayah harus lebih luas untuk penelitian berikutnya sehingga model konseptual dapat digeneralisasi.

Keywords: Corporate Commitment; Customer Loyalty; Supermarket

\section{Pendahuluan}

Industri ritel terutama yang modern mendominasi $7,06 \%$ tempat perdagangan umum, sama dengan 1,131 unit. Dominasi seperti itu terus berkembang mengingat kenyamanan yang disediakan pasar modern dibandingkan dengan yang ditawarkan oleh pasar tradisional. Ada tiga jenis pasar modern yaitu: minimarket, supermarket, dan hipermarket.

Supermarket merupakan sarana berbelanja yang menyediakan berbagai macam produk dari berbagai macam produsen yang ditujukan untuk memenuhi berbagai kebutuhan serta keinginan dari para pelanggan. Banyaknya variasi produk ataupun merek yang tersedia dan dijual di Supermarket, membuat pelanggan kadangkala menjadi bingung atau ragu dalam menentukan pilihan akhir. Sementara kunci keberhasilan setiap perusahaan adalah bagaimana caranya agar pelanggan melakukan pembelian secara berulang atau pelanggan menjadi loyal atau setia.

Berdasarkan sebaran gerainya, geraigerai pasar modern tersebut masih terkonsentrasi di Kota Manado. Pada tahun 
2018, dari 139 gerai pasar modern, 72\% diantaranya berlokasi di Kota Manado. Sementara 28\% gerai pasar modern tersebar di Kabupaten dan Kota lainnya di Provinsi Sulawesi Utara (Dinas Perindag Provinsi Sulut). Bisnis ritel selain menjual barang, juga disertai dengan berbagai layanan. Oleh karena itu pelayanan pelanggan harus menjadi perhatian yang utama bagi para pebisnis di bidang ritel. Semakin berkomitmen perusahaan melalui pelayanan yang diberikan, maka akan menciptakan loyalitas pelanggan semakin baik pula. Sejumlah penelitian menyarankan bahwa komitmen adalah inti daripada semua hubungan kerja yang sukses dan bahwa komitmen merupakan pedoman penting dalam hubungan jangka panjang yang sukses (Anderson dan Narus, 1990).

Teori Komitmen-Kepercayaan adalah kelanjutan dari hubungan jangka panjang. Komitmen serta kepercayaan adalah dua faktor mendasar yang harus ada untuk hubungan yang sukses. Relationship marketing melibatkan pembentukan ikatan dengan pelanggan dengan memenuhi kebutuhan mereka dan menghormati komitmen. Alih-alih mengejar keuntungan jangka pendek, bisnis mengikuti prinsipprinsip relationship marketing yang membentuk ikatan jangka panjang dengan pelanggan mereka. Akibatnya, pelanggan mempercayai bisnis ini, dan loyalitas timbal balik membantu kedua belah pihak memenuhi kebutuhan mereka (Morgan dan Hunt, 1994).

Kamus Besar Bahasa Indonesia (KBBI) mendefinisikan komitmen sebagai "perjanjian (keterikatan) untuk melakukan sesuatu; kontrak" (Alwi, 2007). Dalam literatur relationship marketing, konsep komitmen memainkan peran sentral, karena komitmen merupakan karakteristik utama dari model relationship marketing (Morgan dan Hunt, 1994). Sejumlah penelitian menyarankan bahwa komitmen merupakan inti daripada semua hubungan kerja yang sukses dan bahwa komitmen merupakan pedoman penting dalam hubungan jangka panjang yang sukses (Anderson dan Narus, 1990). Komitmen dipandang sebagai keinginan abadi untuk menjaga hubungan (Moorman et al, 1992). Tujuan jangka panjang ini diperkuat dalam hubungan yang menjalin kontak langsung dan intensif dengan mitra hubungan dan melibatkan mitra dalam dialog (Diller, 2000). Apabila komitmen perusahaan benar-benar dilakukan, maka dipastikan pelanggan menjadi loyal.

Assael (1995) mendefinisikan loyalitas sebagai suatu sikap yang positif terhadap sesuatu yang menghasilkan pembelian yang konsisten dari waktu ke waktu. Loyalitas pelanggan adalah komitmen pelanggan untuk membeli produk dengan cara terus-menerus pada masa mendatang (Liu, 2007). Ketika pelanggan membeli produk atau jasa yang berulang-ulang, pelanggan juga menilai positif terhadap barang dan jasa tersebut, sehingga pelanggan tersebut dikatakan loyal.

Program loyalitas pelanggan merupakan bagian dari aktivitas pengembangan hubungan yang banyak dikembangkan oleh berbagai organisasi. Aktivitas pengembangan hubungan adalah ketika pelanggan membeli produk atau jasa yang berulang-ulang, pelanggan juga menilai positif terhadap barang dan jasa yang ditawarkan oleh organisasi jasa tersebut sehingga pelanggan tersebut dikatakan loyal (Liu, 2007). Oxford Dictionary (Blackburn, 2016) mendefinisikan loyalitas sebagai "kemauan untuk melindungi seseorang, baik secara fisik maupun emosi". Penelitian Ha et al. (2015) menunjukkan hubungan yang signifikan antara Loyalitas Pelanggan dan dimensi kualitas layanan seperti Aspek Fisik dan Pemecahan Masalah. Kontribusi kualitas layanan terhadap kepuasan pelanggan, dan pada gilirannya, terhadap kinerja perusahaan telah lama dikenal. Hasil penelitian ini memberikan bukti empiris yang penting untuk mengevaluasi kualitas layanan ritel saat diterapkan dalam kasus supermarket elektronik di Vietnam. Terdapat beberapa cara yang dapat ditempuh untuk mengidentifikasi dan mengungkapkan kebaruan (novelty) penelitian yaitu dengan mengidentifikasi variabel baru, merumuskan variabel turunan, dan melakukan kompilasi (Solimun dkk, 2019). Variabel baru dalam penelitian ini adalah komitmen perusahaan, sedangkan penelitian terdahulu banyak meneliti tentang komitmen pelanggan. Variabel komitmen perusahaan adalah suatu upaya dalam pemenuhan janji perusahaan bagi pelanggannya, sehingga pada gilirannya menimbulkan tingkat kepercayaan yang 
tinggi pada pelanggan. Penelitian ini menganalisis bahwa loyalitas pelanggan supermarket, sangat ditentukan oleh komitmen perusahaan.

Berdasarkan kajian teori dan penelitian terdahulu, diduga variabel komitmen perusahaan berpengaruh secara signifikan terhadap loyalitas pelanggan. Hipotesis penelitian dirumuskan sebagai berikut:

$\mathrm{H}_{1}$ : Variabel komitmen perusahaan berpengaruh secara signifikan terhadap loyalitas pelanggan.

Hipotesis tersebut digambarkan ke dalam model hipotesis sebagaimana ditunjukkan pada Gambar 1.

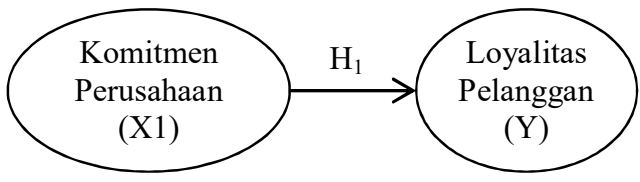

Gambar 1. Model Hipotesis Penelitian

\section{Metode}

Jenis penelitian ini adalah kuantitatif dengan metode survei. Lokasi penelitian di kota Manado, dengan target penelitian adalah pelanggan supermarket. Alasan mengapa diambil kota Manado, adalah: (a) Populasi yang lebih padat dibandingkan dengan kota / kabupaten lain di Sulawesi Utara, yaitu: 425.634 jiwa (Sulut dalam Angka Tahun 2017); (b) Jumlah supermarket yang lebih banyak dan tersebar merata dibandingkan dengan kota / kabupaten lain di Provinsi Sulawesi Utara.

Obyek penelitian adalah pelanggan supermarket di Kota Manado yang tidak diketahui jumlahnya. Hair et al. (2010) menyarankan rumus yang diambil untuk menentukan jumlah populasi yang tidak diketahui jumlahnya bagi suatu penelitian adalah 5 kali dari jumlah item pertanyaan yang dipergunakan dalam penelitian. Jumlah item pertanyaan adalah 14, maka ketika dikalikan dengan 5 diperoleh jumlah populasinya sebanyak 70 orang pelanggan.

Metode pengambilan sampel menggunakan purposive sampling. Kriteria sampel adalah: (a) Frekuensi berbelanja di supermarket sudah lebih dari dua kali sebulan; (b) Berusia lebih dari 18 tahun, sejak mulai usia itu, seseorang dapat membuat keputusan berbelanja di supermarket.

Upaya untuk mendapatkan partisipasi maksimum dari responden dalam mengisi kuesioner penelitian, peneliti menggunakan waktu luang responden ketika mereka sedang mengantri di depan kasir untuk melakukan pembayaran atau ketika pelanggan sedang santai duduk di depan area supermarket. Diusahakan agar responden tidak akan merasa repot untuk berbelanja, karena diminta mengisi kuesioner.

Operasionalisasi konsep didasarkan atas teori yang ada kemudian diturunkan dalam bentuk dimensi dan indikator/item pertanyaan sesuai dengan kondisi di lapangan. Untuk pengukuran variabel digunakan Skala Likert dengan menggunakan skala penilaian sangat tidak setuju dengan bobot 1 sampai dengan sangat setuju dengan bobot 5 (Riduwan, 2003).

Variabel penelitian meliputi variabel eksogen dan variabel endogen, yaitu komitmen perusahaan (X) dan loyalitas pelanggan (Y). Komitmen perusahaan didefinisikan sebagai perjanjian atau kontrak serta keinginan abadi untuk menjaga hubungan. Indikator komitmen perusahaan yang digunakan meliputi: Bauran produk, harga, diskon, layanan call centre, suasana toko, dan promosi.

Loyalitas Pelanggan didefinisikan sebagai komitmen para pelanggan untuk membeli produk atau jasa atau mendukung kembali produk atau jasa supermarket atau swalayan. Indikator Loyalitas Pelanggan meliputi: pelanggan yang aktif, dukungan pelanggan, dan frekuensi berbelanja.

Rincian mengenai indikator variabel dan sumber rujukannya ditampilkan pada Tabel 1 .

Data dianalisis menggunakan SPSS. Untuk menguji pengaruh komitmen perusahaan terhadap loyalitas pelanggan digunakan metode analisis regresi linier sederhana dengan rumus sebagai berikut:

$$
\mathrm{Y}=\mathrm{a}+\mathrm{bX}
$$


Tabel 1. Variabel, Indikator dan Sumber Rujukan

\begin{tabular}{|c|c|c|c|}
\hline No. & Variabel & Indikator & Sumber \\
\hline 1. & $\begin{array}{l}\text { Komitmen } \\
\text { Perusahaan } \\
\text { (X) }\end{array}$ & $\begin{array}{l}\text { a. } \text { Bauran Produk } \\
-\quad \text { Produk berkualitas }\left(\mathrm{X}_{1.1}\right) \\
-\quad \text { Produk beragam dan lengkap }\left(\mathrm{X}_{1.2}\right) \\
\text { b. Harga } \\
-\quad \text { Harga yang terjangkau }\left(\mathrm{X}_{1.3}\right) \\
\text { c. } \text { Diskon Harga } \\
-\quad \text { Potongan harga dan poin bagi pemilik member } \\
\quad \text { card }\left(\mathrm{X}_{1.4}\right) \\
\text { d. } \text { Layanan call centre } \\
-\quad \text { Layanan keluhan dan informasi melalui layanan } \\
\quad \text { bebas pulsa }\left(\mathrm{X}_{1.5}\right) \\
\text { e. } \text { Suasana Toko } \\
-\quad \text { Ruangan toko yang sejuk }\left(\mathrm{X}_{1.6}\right) \\
\text { - } \quad \text { Ruangan toko yqng lapang }\left(\mathrm{X}_{1.7}\right) \\
\text { f. Promosi } \\
\text { - } \quad \text { Promo produk (Katalog, } \mathrm{x} \text { banner })\left(\mathrm{X}_{1.8}\right) \\
\text { g. Lokasi } \\
\text { - } \quad \text { Fasilitas parkir }\left(\mathrm{X}_{1.9}\right) \\
\text { - } \quad \text { Lokasi dijangkau kendaraan umum }\left(\mathrm{X}_{1.10}\right) \\
\end{array}$ & $\begin{array}{l}\text { Kotler and } \\
\text { Armstrong (2012) }\end{array}$ \\
\hline 2. & $\begin{array}{l}\text { Loyalitas } \\
\text { Pelanggan } \\
\text { (Y) }\end{array}$ & $\begin{array}{l}\text { a. } \text { Pelanggan aktif } \\
-\quad \text { Aktif berbelanja }\left(\mathrm{Y}_{1.1}\right) \\
\text { b. } \text { Dukungan pelanggan } \\
-\quad \text { Mengajak orang lain belanja }\left(\mathrm{Y}_{1.2}\right) \\
-\quad \text { Belanja berulang-ulang }\left(\mathrm{Y}_{1.3}\right) \\
\text { c. } \text { Frekuensi berbelanja } \\
-\quad \text { Intensif/rutin berbelanja }\left(\mathrm{Y}_{1.4}\right) \\
\end{array}$ & $\begin{array}{l}\text { Liu, (2007) } \\
\text { Bloemer et al., } \\
\text { (1999) }\end{array}$ \\
\hline
\end{tabular}

Untuk mengetahui signifikansi pengaruh variabel komitmen perusahaan terhadap loyalitas pelanggan, maka dilakukan prosedur uji t pada masing-masing variable. Rumus uji $\mathrm{t}$ adalah sebagai berikut:

$$
t=\frac{b}{s e b}
$$

Keterangan:

$\mathrm{b} \quad=$ Koefisien regresi

seb $=$ Standar error

Apabila nilai $t_{\text {hitung }}$ lebih besar daripada $t_{\text {tabel }}$ dengan taraf signifikansi $(\alpha) 5 \%$, maka hipotesis penelitian diterima. Artinya variabel komitmen perusahaan berpengaruh signifikan terhadap loyalitas pelanggan. Namun, jika $t_{\text {hitung }}$ lebih kecil atau sama dengan nilai $t_{\text {tabel }}$ dengan taraf signifikansi $(\alpha) 5 \%$, maka hipotesis ditolak. Artinya komitmen perusahaan tidak berpengaruh signifikan terhadap loyalitas pelanggan.

\section{Hasil}

Kriteria uji validitas instrumen penelitian adalah bahwa jika koefisien korelasi tiap butir dengan skor total variabel $\left(\mathrm{r}_{\mathrm{iT}}\right)$ lebih besar daripada koefisien korelasi tabel $\left(r_{\text {tabel }}=0,3494\right)$, maka butir dari angket/kuesioner tersebut dinyatakan valid, artinya mampu mengukur variabel yang ingin diukur. Berdasarkan ringkasan hasil uji validitas instrumen penelitian dimana untuk variabel komitmen perusahaan terdiri dari 10 item dan variabel loyalitas pelanggan terdiri dari 4 item, diperoleh hasil bahwa semua nilai koefisien korelasi setiap butir pertanyaan dengan skor total variabel $\left(r_{i T}\right)$ adalah lebih besar daripada koefisien korelasi tabel $\left(\mathrm{r}_{\text {tabel }}=0,3494\right)$. Dengan demikian semua butir pertanyaan dalam angket tersebut adalah valid atau mampu mengukur variabel tersebut. Seluruh butir pertanyaan dapat digunakan sebagai alat pengumpul data. Ringkasan hasil uji validitas instrumen penelitian ditunjukkan pada Tabel 2. 
Tabel 2. Uji Validitas Instrumen

\begin{tabular}{|c|c|c|c|}
\hline Variabel & Item & $\begin{array}{c}\text { Koefisien } \\
\text { Korelasi }\end{array}$ & Keterangan \\
\hline \multirow{10}{*}{$\begin{array}{c}\text { Komitmen } \\
\text { Perusahaan } \\
\text { (X1) }\end{array}$} & $\mathrm{X} 1.1$ & $0,657>0,349$ & Valid \\
\hline & $\mathrm{X} 1.2$ & $0,634>0,349$ & Valid \\
\hline & $\mathrm{X} 1.3$ & $0,559>0,349$ & Valid \\
\hline & X1.4 & $0,544>0,349$ & Valid \\
\hline & $\mathrm{X} 1.5$ & $0,621>0,349$ & Valid \\
\hline & X1.6 & $0,468>0,349$ & Valid \\
\hline & $\mathrm{X} 1.7$ & $0,611>0,349$ & Valid \\
\hline & $\mathrm{X} 1.8$ & $0,722>0,349$ & Valid \\
\hline & X1.9 & $0,704>0,349$ & Valid \\
\hline & $\mathrm{X} 1.10$ & $0,697>0,349$ & Valid \\
\hline \multirow{4}{*}{$\begin{array}{l}\text { Loyalitas } \\
\text { Pelanggan } \\
\text { (Y1) }\end{array}$} & Y1.1 & $0,811>0,349$ & Valid \\
\hline & Y1.2 & $0,750>0,349$ & Valid \\
\hline & Y1.3 & $0,792>0,349$ & Valid \\
\hline & Y1.4 & $0,878>0,349$ & Valid \\
\hline
\end{tabular}

Sumber: data primer, diolah (2019)

Kriteria uji reliabilitas instrumen penelitian adalah bahwa jika nilai Cronbach's Alpha lebih besar daripada 0,6, maka instrumen penelitian tersebut dinyatakan reliabel atau konsisten dalam mengukur variabel tersebut. Berdasarkan ringkasan hasil pengujian reliabilitas instrumen penelitian dimana untuk variabel komitmen perusahaan terdiri dari 10 item dan variabel loyalitas pelanggan terdiri dari 4 item, diketahui bahwa nilai Cronbach's Alpha lebih besar daripada 0,6, oleh karenanya semua butir instrumen penelitian dinyatakan reliabel. Butir-butir dalam kuesioner dapat dipergunakan sebagai alat pengumpul data. Adapun ringkasan hasil uji reliabilitas ditunjukkan pada Tabel 3.

Tabel 3. Pengujian Reliabilitas Instrumen

\begin{tabular}{lcl}
\hline \multicolumn{1}{c}{ Variabel } & $\begin{array}{c}\text { Cronbach's } \\
\text { Alpha }\end{array}$ & Keterangan \\
\hline $\begin{array}{l}\text { Komitmen } \\
\text { Perusahaan }\end{array}$ & 0,754 & Reliabel \\
\hline $\begin{array}{l}\text { Loyalitas } \\
\text { Pelanggan }\end{array}$ & 0,818 & Reliabel \\
\hline Sumber: data primer & & \\
\hline
\end{tabular}

Sumber: data primer, diolah (2019)

Tabel 4 menunjukkan bahwa mayoritas responden adalah dari jenis kelamin laki-laki yaitu sebanyak $58,6 \%$ dan sisanya sebanyak $41,4 \%$ berjenis kelamin perempuan. Berdasarkan Tabel 4 diketahui bahwa sebagian besar usia responden masih dalam rentang usia produktif. Usia sebagian besar responden adalah pada rentang usia antara 26 sampai dengan 35 tahun, yaitu 52,9\%. Sementara pada usia rentang 36-45 tahun ada sebanyak $30 \%$, dan paling kecil ada pada rentang usia $<25$ tahun yaitu sebanyak $2,9 \%$ responden. Hasil analisis deskriptif pada Tabel 4 menunjukkan bahwa mayoritas responden memiliki pendidikan dengan tingkat SLTA yaitu sebesar $57.10 \%$, sementara ada $10,0 \%$ yang berpendidikan $\mathrm{S} 1$ dan S2. Pada tingkat Diploma ada sebanyak $31,4 \%$, sedangkan yang berpendidikan SLTP sebesar 1,4\%. Dari hasil analisis pada tabel 3, terlihat bahwa sebagian besar pekerjaan responden adalah PNS (65,7\%). Sementara $15,7 \%$ adalah tenaga Honor/Kontrak dan $14,3 \%$ adalah karyawan swasta. Hanya 1,4\% yang memiliki pekerjaan sebagai karyawan tetap BUMN/BUMD.

Sebagian besar dari responden (50\%) telah berbelanja cukup lama di supermarketsupermarket yang ada di kota Manado, yaitu rentang antara 5 - 10 tahun. Berikut adalah lama berbelanja responden, dimana responden yang berbelanja $<5$ tahun ada sebanyak 3 responden $(4,3 \%)$, sementara yang berbelanja selama lebih dari 10 tahun ada sebanyak 32 responden (45,7\%). Hasil analisis menunjukkan bahwa sebagian besar responden memilki frekuensi berbelanja diatas 10x yaitu sebanyak 29 responden $(41,4 \%), \quad$ sementara 20 responden menyatakan frekuensi belanja kurang dari 5 kali dalam dua bulan terakhir. Adapun frekuensi berbelanja 5 - 10 kali ada sebanyak 21 responden.

Berdasarkan analisis pada tabel 4, pengeluaran berbelanja sebagian besar responden $(57,1 \%)$ setiap bulannya adalah rentang antara Rp. 500.000 sampai dengan Rp. 1.000.000, biasanya mereka berbelanja kebutuahn sehari-hari keperluan rumah tangga. Sementara ada sekitar 24,3\% responden yang memiliki pengeluaran untuk berbelana di atas Rp. 1.000.000,-, dan ada sekitar $18,6 \%$ yang memiliki pengeluaran di bawah Rp. 500.000.

Pemegang peran untuk berbelanja sebagian besar menyatakan dari orang tua $(47,1 \%)$ memiliki peranan yang sangat besar, sementara peranan anak adalah sebesar $31,4 \%$. Untuk diri sendiri memiliki peranan 
$17,1 \%$ dan pasangan (suami/istri) peranan mereka hanya sebesar $4,3 \%$.

\section{Tabel 4. Informasi Demografi}

\begin{tabular}{|c|c|c|}
\hline Karakteristik & $\begin{array}{l}\text { Frekuensi } \\
(\mathrm{N}-70)\end{array}$ & $\begin{array}{c}\text { Persentase } \\
(\%)\end{array}$ \\
\hline $\begin{array}{l}\text { Jenis kelamin } \\
\text { Laki-laki } \\
\text { Perempuan }\end{array}$ & $\begin{array}{l}41 \\
29\end{array}$ & $\begin{array}{l}58,6 \\
41,4\end{array}$ \\
\hline $\begin{array}{l}\text { Usia } \\
<25 \text { thn } \\
26-35 \text { thn } \\
36-45 \text { thn } \\
>46 \text { thn }\end{array}$ & $\begin{array}{r}2 \\
37 \\
21 \\
10\end{array}$ & $\begin{array}{r}2,9 \\
52,9 \\
30,0 \\
14,3\end{array}$ \\
\hline $\begin{array}{l}\text { Pendidikan } \\
\text { SLTA } \\
\text { Diploma } \\
\text { Sarjana } \\
\text { (S1)/Magister (S2) }\end{array}$ & $\begin{array}{r}40 \\
22 \\
8\end{array}$ & $\begin{array}{l}57,1 \\
31,4 \\
11,4\end{array}$ \\
\hline $\begin{array}{l}\text { Pekerjaan } \\
\text { Karyawan Tetap } \\
\text { BUMN/BUMD }\end{array}$ & 1 & 1,4 \\
\hline $\begin{array}{l}\text { Tenaga } \\
\text { Honor/Kontrak }\end{array}$ & 11 & 15,7 \\
\hline $\begin{array}{l}\text { Karyawan Swasta } \\
\text { PNS } \\
\text { TNI/POLRI }\end{array}$ & $\begin{array}{r}10 \\
46 \\
2\end{array}$ & $\begin{array}{r}14,3 \\
65,7 \\
2,9\end{array}$ \\
\hline $\begin{array}{l}\text { Lama berbelanja } \\
<5 \text { thn } \\
5-10 \text { thm } \\
>10 \text { thn }\end{array}$ & $\begin{array}{r}3 \\
35 \\
32 \\
\end{array}$ & $\begin{array}{r}4,3 \\
50,0 \\
45,7 \\
\end{array}$ \\
\hline $\begin{array}{l}\text { Frekuensi berbelanja } \\
<5 \text { kali } \\
5-10 \text { kali } \\
>10 \text { kali }\end{array}$ & $\begin{array}{l}20 \\
21 \\
29\end{array}$ & $\begin{array}{l}28,6 \\
30,0 \\
41,4\end{array}$ \\
\hline $\begin{array}{l}\text { Pengeluaran belanja } \\
<\text { Rp 500.000,- } \\
\text { Rp 500.000,-- Rp } \\
1.000 .000,- \\
>\text { Rp 1.000.000,- }\end{array}$ & $\begin{array}{l}13 \\
40\end{array}$ & $\begin{array}{l}18,6 \\
57,1\end{array}$ \\
\hline $\begin{array}{l}\text { Peran dalam belanja } \\
\text { Suami/ Isteri } \\
\text { Orangtua } \\
\text { Anak } \\
\text { Diri sendiri }\end{array}$ & $\begin{array}{r}3 \\
33 \\
22 \\
12\end{array}$ & $\begin{array}{r}4,3 \\
47,1 \\
31,4 \\
17,1\end{array}$ \\
\hline $\begin{array}{l}\text { Alasan berbelanja } \\
\text { Memiliki kasir yang } \\
\text { banyak }\end{array}$ & 52 & 74,3 \\
\hline $\begin{array}{l}\text { Tersedianya ATM, } \\
\text { Wifi, Food court serta } \\
\text { tempat parkir }\end{array}$ & 18 & 25,7 \\
\hline
\end{tabular}

Sumber: data primer, diolah (2019)

Keluarga berperan penting dalam mempengaruhi pribadi dan karakter individu. Hal ini karena di dalam keluarga akan terjadi rata-rata intensitas pembicaraan setiap hari, bertukar pikiran, dan lain sebagainya. Itulah sebabnya orangtua yang berperan paling besar dalam mempengaruhi responden dalam berbelanja di supermarket. Selain itu yang tidak kalah pentingnya bagi setiap pelanggan berbelanja di supermarket adalah pemilihan lokasi. Pemilihan suatu lokasi supermarket didasarkan pada alasan responden untuk berbelanja. Berdasarkan hasil survey didapat bahwa sebagian besar responden 74,3\% menyatakan alasan berbelanja karena adanya kebutuhan kasir yang banyak, karena seringkali ketika berbelanja harus mengantri cukup lama yang mengakibatkan kebosanan bagi pelanggan tersebut. Alasan berbelanja lainnya di supermarket yakni adanya kasir yang banyak. $25,7 \%$ responden yang menyatakan bahwa perlu adanya kasir yang banyak, karena jika supermarket hanya menyediakan kasir yang terbatas seringkali ketika berbelanja harus mengantri cukup lama yang mengakibatkan kebosanan bagi pelanggan tersebut.

Hasil analisis pada tabel 5 menunjukkan bahwasanya variabel komitmen perusahaan dipersepsikan baik (rata-rata variabel 4.13). Hal ini menunjukkan supermarket memiliki kemampuan untuk memenuhi apa yang menjadi komitmen perusahaan. Adapun item yang paling berpengaruh terhadap komitmen perusahaan adalah penataan ruangan supermarket yang luas (X17) dengan nilai rata-rata skor 4.32. Beberapa supermarket masih didapati jarak antara rak/lemari yang satu dengan yang lainnya sangat berdekatan atau kurang lebar, sehingga pelanggan kurang leluasa berjalan melewati setiap rak/lemari tersebut. Berdasarkan hasil survey bahwa supermarket yang dikunjungi responden telah memenuhi komitmennya, dengan menyediakan ruangan yang lapang atau tidak sempit sehingga responden merasa nyaman dan leluasa dalam berbelanja.

Tabel 5 menunjukkan distribusi persepsi responden terhadap variabel komitmen perusahaan.

Hasil analisis statistik deskriptif terhadap variabel loyalitas pelanggan (Y) seperti yang ditunjukkan pada tabel 6, didapat nilai rata-rata variabel loyalitas pelanggan sebesar 4.01. Hal ini menunjukkan bahwa loyalitas pelanggan dipersepsikan baik 
Tabel 5. Distribusi Persepsi Responden dan Rata-Rata Skor Variabel Komitmen Perusahaan

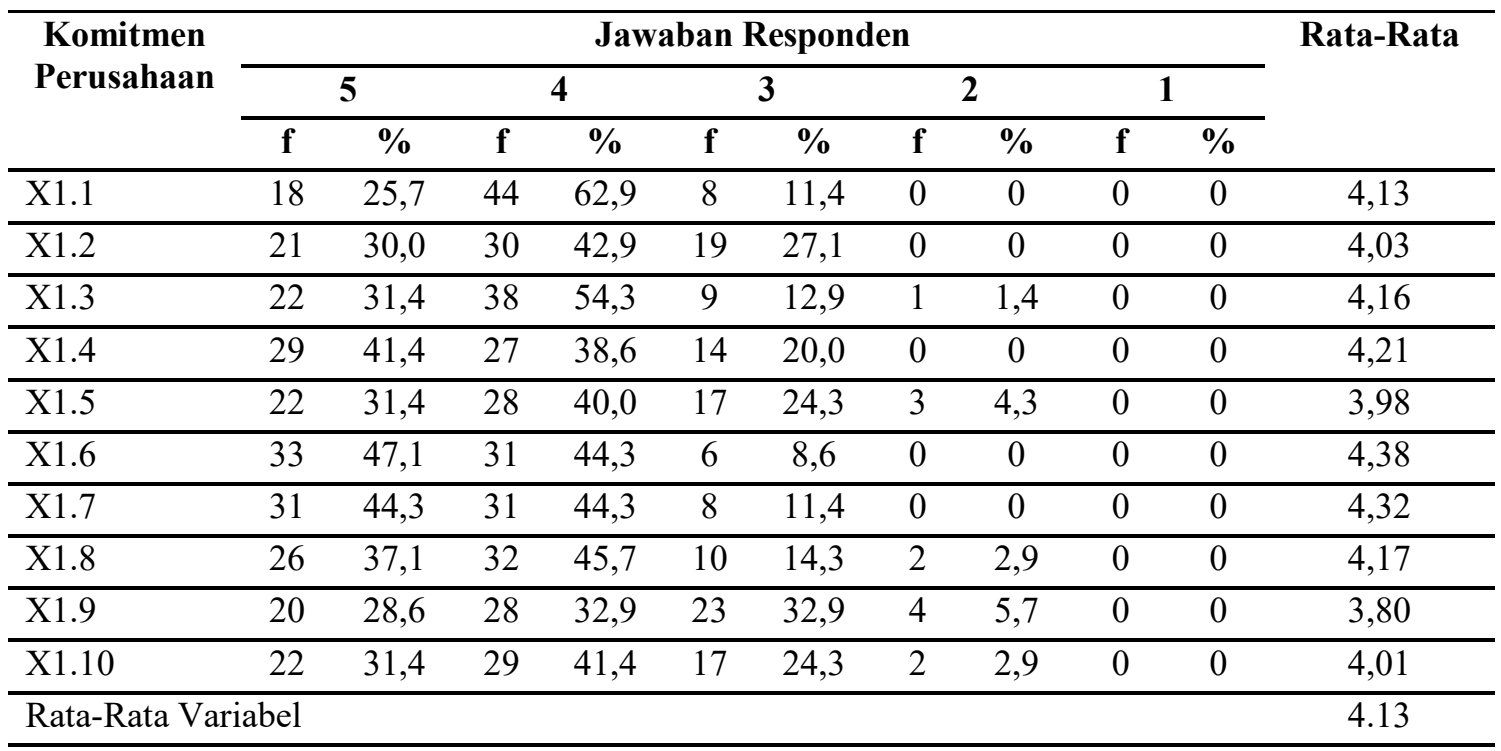

Sumber: data primer, diolah (2019)

oleh responden, adapun item yang memiliki nilai paling besar adalah mengajak atau merekomendasikan orang lain untuk membeli di supermarket tersebut dengan nilai rata-rata skor 4.23.

Tabel 6 menunjukkan distribusi persepsi responden terhadap variabel loyalitas pelanggan.

Hasil analisis korelasi, ditunjukkan pada Tabel 7, dimana nilai signifikansi dari masing- masing nilai korelasi $<0.05$. Hubungan kedua variabel terbukti signifikan, sementara kekuatan adalah cukup.

Analisis regresi linier sederhana pada penelitian ini dimaksudkan untuk melihat sejauh mana kemampuan suatu model menerangkan variasi variabel dependen.
Hasil analisis Regresi Linear Sederhana ditunjukkan pada Tabel 8.

Tabel 7. Uji Korelasi

\begin{tabular}{|c|c|c|c|}
\hline \multicolumn{2}{|c|}{ Correlations } & $\mathrm{X1}$ & Y1 \\
\hline \multirow[t]{3}{*}{$\mathrm{X} 1$} & $\begin{array}{l}\text { Pearson } \\
\text { Correlation }\end{array}$ & 1 & $0,472^{* *}$ \\
\hline & Sig. (2-tailed) & & 0,000 \\
\hline & $\mathrm{N}$ & 70 & 70 \\
\hline \multirow[t]{3}{*}{$\overline{\mathrm{Y} 1}$} & $\begin{array}{l}\text { Pearson } \\
\text { Correlation }\end{array}$ & $0,472^{* *}$ & 1 \\
\hline & Sig. (2-tailed) & 0,000 & \\
\hline & $\mathrm{N}$ & 70 & 70 \\
\hline
\end{tabular}

Berdasarkan tabel 8 dapat diketahui sebuah persamaan regresi linier sebagai berikut:

Tabel 6. Distribusi Frekuensi Variabel Loyalitas Pelanggan

\begin{tabular}{|c|c|c|c|c|c|c|c|c|c|c|c|}
\hline \multirow{3}{*}{$\begin{array}{c}\text { Loyalitas } \\
\text { Pelanggan }\end{array}$} & \multicolumn{10}{|c|}{ Jawaban Responden } & \multirow[t]{3}{*}{ Rata-Rata } \\
\hline & \multicolumn{2}{|c|}{5} & \multicolumn{2}{|c|}{4} & \multicolumn{2}{|c|}{3} & \multicolumn{2}{|c|}{2} & \multicolumn{2}{|c|}{1} & \\
\hline & f & $\%$ & $\mathbf{f}$ & $\%$ & f & $\%$ & $\mathbf{f}$ & $\%$ & $\mathbf{f}$ & $\%$ & \\
\hline Y1.1 & 17 & 24,3 & 36 & 51,4 & 17 & 24,3 & 0 & 0 & 0 & 0 & 4,00 \\
\hline Y1.2 & 28 & 40,0 & 31 & 44,3 & 10 & 14,3 & 1 & 1,4 & 0 & 0 & 4,23 \\
\hline Y1.3 & 14 & 20,0 & 40 & 57,1 & 16 & 22,9 & 0 & 0 & 0 & 0 & 3,97 \\
\hline \multirow[t]{2}{*}{ Y1.4 } & 19 & 27,1 & 22 & 31,4 & 28 & 40 & 1 & 1,4 & 0 & 0 & 3,80 \\
\hline & & & & & & & \multicolumn{4}{|r|}{ iabel } & 4.01 \\
\hline
\end{tabular}

Sumber: data primer, diolah (2019) 
Tabel 8. Hasil Uji Regresi Linier Sederhana

\begin{tabular}{|c|c|c|c|c|c|}
\hline \multirow[t]{2}{*}{ Model } & \multicolumn{2}{|c|}{$\begin{array}{c}\text { Unstandardized } \\
\text { Coefficients }\end{array}$} & \multirow{2}{*}{$\begin{array}{c}\begin{array}{c}\text { Standardized } \\
\text { Coefficients }\end{array} \\
\text { Beta }\end{array}$} & \multirow[t]{2}{*}{$\mathbf{t}$} & \multirow[t]{2}{*}{ Sig. } \\
\hline & $\bar{B}$ & Std. Error & & & \\
\hline (Constant) & 6,138 & 2,259 & & 2,717 & 0,008 \\
\hline $\mathrm{X}$ & 0,240 & 0,054 & 0,472 & 4,412 & 0,000 \\
\hline
\end{tabular}

Sumber: data primer, diolah (2019)

Loyalitas Pelanggan $(\mathrm{Y})=6,138+0,240 \mathrm{X}$

Persamaan regresi di atas dapat dijelaskan sebagai berikut: konstanta sebesar 6,138; artinya jika Komitmen Perusahaan (X) bernilai 0 , maka nilai Loyalitas Pelanggan (Y) adalah 6,138. Koefisien regresi untuk variabel Komitmen Perusahaan (X) sebesar 0,240; artinya jika nilai variabel Komitmen Perusahaan mengalami kenaikan 1\%, maka Loyalitas Pelanggan (Y) akan mengalami peningkatan sebesar 0,240 . Koefisien regresi bernilai positif berarti terdapat hubungan positif antara Komitmen Perusahaan dengan Loyalitas Pelanggan, semakin naik Komitmen Perusahaan maka semakin meningkat pula Loyalitas Pelanggan.

Uji hipotesis dilakukan untuk membuktikan pengaruh variabel bebas (independen) terhadap variasi variabel terikat (dependen). Uji pengaruh dilakukan dengan melihat nilai signifikansi dari masing-masing variabel independen. Bila nilai signifikansinya kurang dari $0.05(\mathrm{Sig} .<0.05)$ maka variabel independen tersebut secara signifikan mempengaruhi variabel dependen. Apabila nilai probabilitas signifikansinya lebih dari 0,05 (Sig $>0,05)$ maka variabel independen tidak berpengaruh signifikan terhadap variabel dependen.

Pengujian hipotesis pengaruh komitmen perusahaan terhadap loyalitas pelanggan. Menunjukkan bahwa variabel komitmen perusahaan (X) memiliki nilai signifikan sebesar 0.000. Nilai tersebut lebih kecil dari 0.05 , maka dapat dikatakan variabel komitmen perusahaan berpengaruh terhadap loyalitas pelanggan (Y). Sehingga hipotesis yang menyatakan bahwa komitmen perusahaan berpengaruh terhadap loyalitas pelanggan diterima pada alpha $=5 \%$.

Koefisien determinasi menunjukkan seberapa jauh kemampuan model yang terbentuk dalam variabel bebas (independen) mampu menerangkan variasi dari variabel dependen. Untuk mengetahui seberapa besar persentasenya dapat dilihat pada Tabel 9. Nilai adjusted $R$ square menunjukkan koefisien determinasi dari variabel independen.

Tabel 9. Uji Koefisien Determinasi

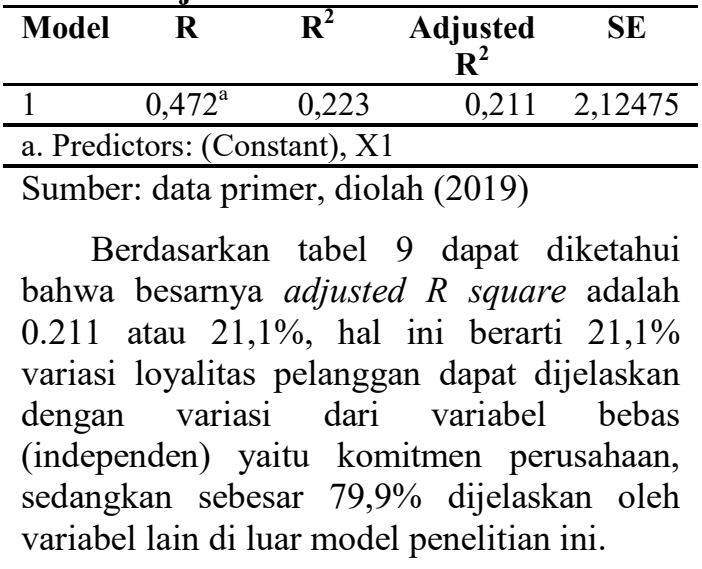

\section{Pembahasan}

Berdasarkan tujuan dan hipotesis penelitian terdapat pengaruh antar variabel yang harus dibuktikan: apakah ada pengaruh antara variabel komitmen perusahaan terhadap variabel loyalitas pelanggan. Atau dengan kata lain, hipotesis yang telah dirumuskan bahwa diduga ada pengaruh yang positif dan signifikan antara komitmen perusahaan terhadap loyalitas pelanggan, diterima atau ditolak.

Berdasarkan uji hipotesis dapat diketahui variabel komitmen perusahaan (X), memiliki nilai signifikan sebesar 0.000 . Nilai tersebut lebih kecil dari 0.05 , maka dapat dikatakan variabel komitmen perusahaan berpengaruh terhadap loyalitas pelanggan (Y). Sehingga hipotesis yang menyatakan bahwa komitmen perusahaan berpengaruh terhadap loyalitas pelanggan diterima.

Berdasarkan hasil analisis pada analisis statistik deskriptif dapat dijelaskan 
bahwasanya variabel komitmen perusahaan (X) dipersepsikan baik (rata-rata variabel 4.13). Hal ini menunjukkan supermarket memiliki kemampuan untuk memenuhi apa yang menjadi komitmen perusahaan. Adapun item yang paling berpengaruh terhadap komitmen perusahaan adalah penataan ruangan yang lapang atau tidak sempit (X1.7) dengan nilai rata-rata skor 4.32. Sedangkan hasil analisis deskriptif terhadap variabel loyalitas $(\mathrm{Y})$, didapat nilai rata-rata variabel loyalitas pelanggan sebesar 4.01. Hal ini menunjukkan bahwa loyalitas pelanggan dipersepsikan baik oleh responden, adapun item yang memiliki nilai paling besar adalah mengajak atau merekomendasikan orang lain untuk membeli di supermarket tersebut dengan nilai rata-rata skor 4.23.

Penelitian ini mendukung hasil penelitian dari Bricci et al. (2016), yang bertujuan untuk menunjukkan pengaruh utama dari komitmen, kepercayaan dan kepuasan pelanggan terhadap loyalitas pelanggan dari sektor distribusi di Portugal. Hasil penelitian menunjukkan bahwa Komitmen pelanggan berpengaruh positif dan langsung pada loyalitas pelanggan, sehingga sangat penting bagi perusahaan ini pada peningkatan pengembangan keterampilan tim, tanggung jawab, memberdayakan karyawan, dan perusahaan dalam arti untuk memenuhi komitmen dan melakukan penciptaan nilai bersama.

Penelitian ini juga memperkuat teoriteori yang sudah ada sebelumnya dengan cara menguji secara empiris konsep komitmen perusahaan sebagai bauran pemasaran ritel (Kotler dan Armstrong, 2012), komponen bauran pemasaran ritel yaitu bauran produk, layanan, suasana toko, harga, promosi, dan lokasi. Melalui Komitmen Perusahaan terhadap Loyalitas Pelanggan, sangat memungkinkan pengelola ritel (Supermarket) untuk mengevaluasi komitmen perusahaan terhadap loyalitas pelanggan. Menguji secara konsep peran sentral komitmen perusahaan dalam relationship marketing (Morgan dan Hunt, 1994). Menguji secara empiris konsep Komitmen Perusahaan guna meningkatkan Loyalitas Pelanggan (Cronin dan Taylor, 1992). Komitmen perusahaan bisa terbentuk bila perusahaan (dalam hal ini supermarket) memberikan keuntungan yang lebih tinggi yang diperoleh pelanggan jika di bandingkan yang diberikan oleh pesaing.

\section{Kesimpulan}

Kesimpulan dari penelitian ini adalah bahwa komitmen perusahaan berpengaruh positif dan signifikan terhadap loyalitas pelanggan. Tinggi rendahnya komitmen perusahaan yang disediakan oleh supermarket di kota Manado akan berpengaruh terhadap loyalitas pelanggan. Semakin tinggi komitmen perusahaan yang dirasakan oleh pelanggan supermarket akan meningkatkan level loyalitas pelanggan. Hasil penelitian ini merupakan temuan baru, dimana penelitian-penelitian terdahulu lebih menekankan pada komitmen pelanggan saja.

Implikasi manajerial dari penelitian ini adalah bahwa para pemimpin supermarket di Manado harus lebih fokus dan lebih menekankan pada dimensi suasana toko yakni tersedianya ruang yang lapang dan nyaman, sehingga ketika dimensi itu dapat dipenuhi maka kepercayaan pelanggan terhadap apa yang dijanjikan oleh manajer supermarket dan itu akan meningkatkan loyalitas pelanggan untuk menyampaikan atau mengajak pada orang lain serta kembali berbelanja lagi di supermarket.

Keterbatasan penelitian ini adalah terbatasnya area penelitian karena hanya membutuhkan satu area yakni kota Manado saja dan hanya di supermarket. Oleh karena itu, untuk penelitian lebih lanjut, cakupan area harus diperluas dan memperluas klasifikasi pasar modern sehingga dapat mencapai semua klasifikasi baik dari minimarket, supermarket, dan hypermarket.

\section{Daftar Referensi}

Alwi, Hasan. (2007). Kamus Besar Bahasa Indonesia. Jakarta: Balai Pustaka.

Anderson, J., and Narus, J. (1990). Business Market Management: Understanding, Creating and Developing Value (2nd ed.). Englewood Cliffs, NJ: PrenticeHall.

Assael, H. (1995), Consumer Behaviour and Marketing Action, Ninth Edition. Boston: Kent Publishing Company. 
Blackburn, Simon. (2016). The Oxford Dictionary of Philosophy. Amerika: Oxford University Press.

Bloemer, J; Ruyter, K; Wetzels ,M. (1999). Linking perceived service quality and service loyalty: a multidimensional perspective. European Journal of Marketing, 33(11, 12), 1082-1106.

Bricci, L., Fragata A, and Antunes J. (2016). The Effects of Trust, Commitment and Satisfaction on Customer Loyalty in the Distribution Sector. Journal of Economics, Business and Management. Vol. 4, No. 2, pp. 173-177.

Cronin Jr, J. J. and Taylor, S. A. (1992). Measuring service quality: a reexamination and Extension. Journal of Marketing, 56 (July), 55-68.

Diller, Hermann. (2000). Customer Loyalty: Fata Morgana or Realistic Goal? Managing Relationships with Customers. In Relationship marketing: Gaining Competitive Advantage through Customer Satisfaction and Customer Retention, edited by Thorsten HenningThurau and Ursula Hansen, Berlin: Springer.

Hair, J. F. Jr., Anderson, R. E., Tatham, R. L., and Black, W. C. (2010). Multivariate Data Analysis. $5^{\text {th }}$ ed. New Jersey: Prentice Hall.
Kotler, Philip and Armstrong, Gary. (2012) Prinsip-prinsip Pemasaran. Edisi ketigabelas Jilid 1. Penerbit Erlangga.

Liu, Y. (2007). The Long term Impact of Loyalty Programs on Consumer Purchase Behavior and Loyalty. Journal of Marketing. 71 (4): 19 - 35.

Moorman, Christine, Rohit Deshpande and Gerald Zaltman. (1992). Factors affecting trust in market research relationships. Journal of Marketing, 57(1): 81-101.

Morgan, Robert M. and Shelby D. Hunt. (1994). The Commitment-Trust Theory of Relationship Marketing. Journal of Marketing 58(3): 20-39.

Ha, N. T., Minh, N. H., Anh, P. C., \& Matsui, Y. (2015). Retailer Service Quality and Customer LoyaltyEmpirical Evidence in Vietnam. Asian Social Science, 11(4): 90-101.

Riduwan, (2003). Skala Pengukuran Variabel-Variabel Penelitian. Cetakan kedua. Bandung: Alfabeta.

Solimun, Armanu, Fernandes Adji Achmad Rinaldo. (2019). Metodologi Penelitian Kuantitatif Perspektif Sistem: Mengungkap Novelty dan Memenuhi Validitas Penelitian. Cetakan Kedua. Malang: UB Press. 